\title{
Criando intimidade, recebendo visibilidade: novas práticas de persuasão na economia da fama
}

\section{Creating intimacy, receiving visibility: new practices of persuasion in the economy of fame}

\author{
Bruno Campanella ${ }^{1}$ \\ Joana d'Arc de Nantes ${ }^{2}$ \\ Paula Fernandes ${ }^{3}$
}

Resumo: Este artigo analisa formas de negociação de intimidade e afeto entre ídolos e seus admiradores dentro de ações que visam à promoção da celebridade. Nessas dinâmicas, a celebridade desenvolve um tipo de intimidade com seus fãs que os motiva a participar de verdadeiras cruzadas nas mídias sociais que objetivam a produção de maior atenção midiática para seu ídolo. As discussões apresentadas são baseadas no exame de estudos de caso envolvendo duas celebridades que adotam esse tipo de estratégia de persuasão: a cantora Valesca Popozuda e a youtuber Kéfera Buchmann.

Palavras-chave: celebridade; fã; intimidade; visibilidade.
Abstract: This article aims to analyse some forms of negotiating intimacy and affection between idols and their admirers, within actions that aim at the promotion of the former. In these dynamics, the celebrity develops a kind of inti- macy with its fans that motivates them to participate in real crusades in the social media, which aspire to the production of more media attention for their idol. The discussions presented in this piece are based on the examination of case studies
1 Universidade Federal Fluminense (UFF). Niterói, RJ, Brasil.
https://orcid.org/0000-0003-4040-3472 E-mail: brunocampanella@yahoo.com
2 Universidade Federal Fluminense (UFF). Niterói, RJ, Brasil.
https://orcid.org/0000-0001-6437-240XＥ-mail: joanadarc.nantes@gmail.com
3 Universidade Federal Fluminense (UFF). Niterói, RJ, Brasil.
https://orcid.org/0000-0002-0983-1527 E-mail: paulafergc@gmail.com 
BRUNO CAMPANELLA | JOANA D'ARC DE NANTES | PAULA FERNANDES 367

investigating strategies of persuasion adopted by two celebrities: the funk singer Valesca Popozuda and youtuber Kéfera Buchmann.

Keywords: celebrity; fan; intimacy; visibility. 


\section{Introdução}

A ideia de que as celebridades dependem de estratégias para se estabelecer e se manter em evidência já é bastante consolidada. Rein, Kotler e Stoller (1997), por exemplo, propõem diferentes estágios históricos da indústria da celebridade. ${ }^{4}$ Segundo os autores, é possível identificar táticas relativamente artesanais para a produção da fama de indivíduos "comuns" desde períodos pré-industriais no século XVIII. Ao longo do tempo, contudo, especialmente a partir do século XX, tais ações foram se sofisticando, criando uma verdadeira indústria que envolve inúmeros profissionais e grandes empresas de mídia. Consultores, fotógrafos, agentes, coachers e especialistas em relações-públicas são apresentados como elementos fundamentais de uma dinâmica responsável pela construção de carreiras que, em alguns casos, se estruturam na capacidade de o indivíduo se manter em evidência nas mídias. Escrevendo no final da década de 1990, Rein, Kotler e Stoller (1997, p. 40) também sugerem que o mais recente estágio de desenvolvimento desse fenômeno seria marcado por sua descentralização geográfica. Ou seja, eles argumentam que a indústria de celebridades não mais existe unicamente em grandes centros urbanos como Nova York ou Los Angeles, podendo igualmente ser encontrada em cidades ou regiões periféricas.

A atual popularização dos sites de redes sociais, entretanto, ajudou a consolidar um novo movimento de descentralização dessa indústria, que ocorre por meio da participação de fãs e outros agentes "não profissionais" que se tornam cada vez mais importantes na produção da fama. Facebook, Twitter, Instagram e Snapchat, por exemplo, têm possibilitado uma relação mais direta entre seguidores e celebridades. A conexão entre eles passou a prescindir da intermediação de gravadoras, redes de televisão, portais de notícias ou estúdios de cinema.

Essa descentralização nas relações entre as celebridades e seus seguidores permite maior autonomia a artistas e aspirantes à fama na difícil tarefa de aumentar o capital de visibilidade (HEINICH, 2012)

4 Os quatro estágios são: estágio da indústria artesanal, estágio de industrialização precoce, industrialização tardia e estágio de descentralização. 
em uma sociedade caracterizada por uma crescente disputa por atenção (STERNHEIMER, 2011). Se, tradicionalmente, um ator de telenovela dependia da emissora a qual estava vinculado para se manter em evidência e construir uma relação com seus fãs (COELHO, 1999; TURNER, BONNER e MARSHALL, 2000), agora ele pode cumprir tais tarefas sem qualquer tipo de intermediação institucional - basta ter uma presença ativa nas mídias sociais.

No Brasil, um sintoma significativo desse processo de descentralização foi o encerramento, em abril de 2017, do portal de notícias sobre celebridades Ego, do Grupo Globo. Segundo o comunicado da empresa, o fim do site está associado à expansão de práticas interacionais entre ídolos e fãs por meio das mídias sociais (GLOBO EMITE COMUNICADO..., 2017). Nessa conjuntura, sites que noticiam a vida de celebridades passaram a reproduzir imagens e informações coletadas diretamente dos perfis dos famosos em plataformas como Instagram ou Facebook, apresentando-se, muitas vezes, como meros replicadores de conteúdo.

A despeito dessas transformações, a simples adesão de celebridades a mídias com estruturas mais abertas não é condição suficiente para impulsionar o grau de exposição pública dessas personalidades. Conforme visto nos estudos de caso apresentados, algumas celebridades utilizam seus perfis de modo a atrair seguidores que não somente se interessem pelas suas postagens, mas também estejam dispostos a se engajar na divulgação e popularização do perfil em questão.

Já existem trabalhos analisando diferentes aspectos das dinâmicas entre celebridades e seguidores/fãs em mídias sociais. Baym (2007, 2013), por exemplo, pesquisa novas práticas midiáticas ${ }^{5}$ responsáveis pela reorganização de fronteiras que tradicionalmente mantinham os fãs distantes do convívio pessoal de músicos famosos, permitindo a criação de relações de amizade e afeto entre ambos. Marwick e boyd (2011) também refletem sobre transformações recentes associadas ao relacionamento

5 Sobre o conceito de prática midiática, ver Kramp e colaboradores (2014) e Bräuchler e Postill (2010). 
entre artistas e fãs, porém com ênfase em práticas no Twitter de celebridades que buscam criar uma percepção de autenticidade e intimidade com seus seguidores. Já Baym e Burnett (2009), por sua vez, analisam as implicações das novas relações de trabalho resultantes da atuação de fãs na divulgação de suas bandas musicais preferidas em mídias sociais.

Dentro desse contexto, o presente artigo propõe investigar algumas das motivações responsáveis pela criação de práticas estabelecidas entre celebridades e seguidores. Mais especificamente, busca-se analisar lógicas por trás do esforço empreendido por celebridades que tentam cultivar uma base de fãs e admiradores fiéis nas mídias sociais e, principalmente, entender algumas das razões que levam esses seguidores a se engajar em tal comportamento.

Em determinadas dinâmicas, é possível perceber o surgimento de uma economia de reconhecimento e visibilidade entre celebridade e fã. Nesse processo, a celebridade desenvolve um tipo de intimidade com seus seguidores que os motiva a participar de verdadeiras cruzadas nas mídias sociais com o objetivo de produzir maior atenção midiática para seu ídolo. Celebridade e seguidor estão, desse modo, dentro de um processo que se retroalimenta, caracterizado pela mútua produção de visibilidade com diferentes implicações para ambos.

Para refletir sobre essas questões, este artigo analisa dinâmicas envolvendo Valesca Popozuda e Kéfera Buchmann, personalidades de destaque em diferentes ramos da indústria de entretenimento. A escolha do corpus desta pesquisa é decorrente do ativo envolvimento de ambas em práticas que têm por objetivo persuadir seus fãs e seguidores a produzir capital de visibilidade ${ }^{6}$ para elas (HEINICH, 2012). Kéfera e Valesca promovem iniciativas que estabelecem uma relação direta com seus seguidores como forma de incentivo e reconhecimento pelo esforço empreendido por eles. Assim, é possível observar como as dinâmicas de produção de reconhecimento e visibilidade se articulam de modo a

6 Heinich (2012) define capital de visibilidade como um tipo de capital social ligado à ideia de assimetria de visibilidade entre pessoas famosas e pessoas “comuns”. De acordo com a autora, capital de visibilidade pode ser convertido em capital econômico. 
trazer ganhos simbólicos - e materiais, no caso das celebridades - para as partes envolvidas.

\section{0 processo de produção da celebridade}

Com frequência, reflexões acerca do processo de construção de celebridades costumam ser conectadas a estratégias mercadológicas de diferentes setores da indústria do entretenimento, seja do cinema (MORIN, 1989, 1997; DYER, 1998), do mercado fonográfico (MARSHALL, 1997) ou da televisão (CAMPANELLA, 2012; LANGER, 2006; TOLSON, 2015; TURNER, 2004). Mesmo autores que buscam pensar o fenômeno da celebridade como evidência de transformações mais amplas ocorridas nos séculos XVIII e XIX, algumas conectadas às próprias fontes morais do indivíduo moderno (MOLE, 2007), ou de sua performance em certos contextos sociais (VAN KRIEKEN, 2012) reconhecem a importância de setores da economia capitalista para a consolidação de um interesse generalizado pela vida desses famosos, vistos como não pertencentes à esfera do "comum".

Leo Löwenthal foi um dos primeiros pensadores a articular a popularização das celebridades - ou "ídolos de massa" - dentro de uma matriz ideológica capitalista. Integrante da Escola de Frankfurt, Löwenthal analisou a publicação de biografias de figuras públicas em revistas de variedades entre 1901 e 1941.7 Seus estudos mostram que a grande maioria das biografias publicadas nos primeiros anos do século XX, três quartos delas, eram de políticos, homens de negócios e profissionais de sucesso, os chamados "ídolos da produção" (LÖWENTHAL, 2006). Poucas décadas depois, contudo, a situação mudou drasticamente. Aproximadamente a mesma proporção de publicações, ou seja, entre 67 e $78 \%$ das biografias, dependendo da revista analisada, eram de atores, esportistas e outras personalidades - vindas principalmente da indústria do entretenimento - que tinham detalhes de suas vidas privadas esmiuçadas nas reportagens. Hobbies, viagens e festas eram temas preferidos

7 Löwenthal analisou o The Saturday Evening Post e a revista Collier. 
das biografias desses "ídolos do consumo", que substituíram as antigas narrativas edificantes que retratavam as trajetórias profissionais (e públicas) dos "ídolos da produção" de décadas anteriores. Para Löwenthal, essa mudança indica a crescente valorização de uma gramática ligada ao consumo de estilos de vida que se torna central na formação das aspirações e desejos do indivíduo comum.

Pouco mais de uma década após a publicação do trabalho do sociólogo alemão, Daniel Boorstin também lança uma análise do fenômeno das celebridades, porém com foco diferente. Em vez de examinar a influência da indústria cultural na popularização dos "ídolos do consumo", Boorstin reflete sobre o crescimento das celebridades dentro de uma perspectiva de declínio moral da sociedade. De acordo com o autor, estaríamos entrando numa época dominada por pseudoeventos em que a imagem de um indivíduo seria mais importante que seus feitos (BOORSTIN, 1992, p. 46). O autor defende que as celebridades contemporâneas seriam antíteses dos heróis tradicionais, estes admirados por sua coragem, nobreza ou por feitos extraordinários. Dentro dessa tese, o esforço de criar e difundir a imagem de celebridades é visto como sintoma de uma crescente decadência moral da sociedade moderna, que teria entrado em uma fase de autoilusão.

As contribuições de Löwenthal e Boorstin trazem importantes reflexões acerca das transformações ocorridas no século XX, especialmente no que se refere à expansão do consumo e à mudança no estatuto da imagem na cultura ocidental. No entanto, elas refletem perspectivas dicotômicas de mundo que estabelecem fronteiras fixas entre acontecimentos "sérios" e "edificantes" e aqueles puramente "fúteis" e "consumistas"; experiências "genuínas" e "falsas". Tal visão não ajuda a pensar as ambiguidades e contradições existentes no processo de produção da fama.

Van Krieken (2012, p. 5-8), por exemplo, evita pensar o fenômeno da celebridade por meio de oposições do tipo "heróis autênticos" e "celebridades artificiais", argumentando que personagens famosos de diferentes épocas, sejam nobres, políticos ou artistas, sempre precisaram 
comunicar seus feitos da melhor forma possível para se tornarem reverenciados. "Não pode existir herói ou heroísmo sem uma narrativa compartilhável capaz de construir o heroico", afirma Strate (1994, p. 15) seguindo a mesma linha de Van Krieken. Benjamin Franklin, a rainha Vitória e mesmo Alexandre, o Grande, que ordenou a impressão da imagem de seu rosto nas moedas usadas nos territórios ocupados por seus exércitos na Europa e na Ásia no século IV a.C., despendiam considerável esforço na tarefa de se tornarem conhecidos (BRAUDY, 1986).

É inegável, contudo, que a expansão da indústria cultural e das mídias de massa ajudou na formação de um sistema institucionalizado de criação da fama (GAMSON, 1994) que tem início nos primórdios do cinema (MORIN, 1989, 1997; DYER, 1998) e atinge um patamar sem precedentes no final do século XX.

Os programas de reality show, que ganham grande popularidade na década de 1990, são frequentemente considerados os principais responsáveis pela extraordinária expansão do mercado de celebridades (COLLINS, 2008; GRINDSTAFF e MURRAY, 2015; HOLMES e JERMYN, 2004; TURNER, 2006). Além da rápida popularização desse gênero, praticamente onipresente na atualidade, o mercado televisivo passou, de modo geral, por transformações significativas nos últimos anos. Sua desregulamentação na década de 1990 em diferentes partes do mundo, a entrada relativamente recente de novos canais - decorrente do aumento da demanda em um mercado que, somente no Brasil, quadruplicou o número de assinantes nos últimos sete anos (ESTATÍSTICAS DE TV..., [s. d.]) - e a preferência de produtores de televisão por programas factuais feitos localmente e com baixo custo relativo abriu espaço para um número expressivo de aspirantes à fama. Além das tradicionais personalidades de destaque, como músicos, atores, esportistas e políticos, a classe dos "famosos midiáticos" passa a incluir agora ex-participantes de reality shows, modelos e outros indivíduos sem nenhum talento particular, batizados por Rojek (2001, p. 20-21) de "celetoides", que povoam os mais diversos programas sobre "realidade" e generalidades cotidianas. 
Turner (2004, p. 33-34) sugere que as celebridades adquiriram, nas últimas décadas, um papel crucial na indústria do entretenimento. Elas seriam fundamentais para o movimento de "integração vertical" de conteúdo. Segundo o autor, as celebridades têm, enquanto produto, a capacidade de conectar diferentes mídias e plataformas dentro de um processo que tem como foco a valorização da personalidade individual. Analisando o binômio arte e comercialização, Weinstein (1999, p. 65) apresenta um argumento semelhante ao afirmar que as gravadoras musicais tentam dirigir a atenção dos consumidores para as atitudes e os estilos de vida dos integrantes das bandas para, com isso, vender livros, pôsteres, camisas, DVDs e outros produtos relacionados em vez de comercializar unicamente as músicas.

No entanto, a despeito do grande número de personalidades midiáticas surgindo diariamente, poucas conseguem se estabilizar na indústria do entretenimento e, com isso, sustentar uma carreira longa. No estudo que fizeram sobre a produção de celebridades na Austrália, Turner, Bonner e Marshall (2000, p. 88) mostram como alguns jovens atores de telenovela daquele país dependiam da grande exposição trazida por revistas e programas de variedades para se manterem em evidência. Quando a programação na qual trabalhavam saía do ar e a estrutura promocional que os colocava em destaque mudava de foco, esses atores experimentavam grande dificuldade para manter o grau de interesse dos fãs. Depois de algum tempo de ostracismo, muitos simplesmente abandonavam a carreira artística.

Com o desenvolvimento de tecnologias digitais e da web 2.0, contudo, foram criadas novas práticas que trouxeram mudanças na construção e manutenção da fama, enfraquecendo o controle das grandes corporações midiáticas. Assim, pessoas "comuns" puderam ganhar notoriedade e status de celebridades - ou webcelebridades - devido ao sucesso em distintas mídias sociais sem necessariamente passar pelos meios de comunicação tradicionais. Dentro desse contexto, youtubers e influenciadores digitais ganham destaque no "mundo dos famosos" (KHAMIS, 
ANG e WELLING, 2016) e o público começa a conversar diretamente com seus ídolos e a acompanhar, "em tempo real", a vida deles.

No entanto, sustentar um grande número de seguidores no ambiente virtual não é algo simples. Mesmo celebridades já consagradas enfrentam dificuldades, uma vez que, para se manter em evidência em plataformas como Instagram, Twitter ou Facebook, é necessária uma participação ativa que conjugue estratégias capazes de atrair seguidores e fãs. Nos casos analisados a seguir, Valesca e Kéfera mostram grande capacidade de gerenciamento de seus perfis on-line. Ambas participam de uma economia de troca de visibilidade com seus fãs, que são impelidos a produzir exposição midiática para elas em troca de uma espécie de reconhecimento público de seus esforços.

\section{Valesca e os popofãs: "beijinho no ombro" para a invisibilidade nas mídias}

Muito ativa nas mídias sociais, com perfis no Twitter, Instagram e Facebook, Valesca Popozuda interage constantemente com seus fãs apelidados de "popofãs". É comum ver nos perfis da cantora fotos com seus admiradores, assim como referências diretas a encontros com eles. Os "popofãs" têm tido importante papel em ações para aumentar a projeção de Valesca dentro e fora das mídias sociais, impulsionando, desse modo, seu capital de visibilidade (HEINICH, 2012). Quando a cantora de funk participa de programas televisivos ou de rádio, por exemplo, seus mais devotados seguidores costumam dedicar considerável esforço para ampliar a repercussão de tais acontecimentos. Hashtags como \#Valescanovaiquecola, ${ }^{8}$ \#ValescaNoRaulGil ${ }^{9}$ e \#Valescapopozudanoestrelas ${ }^{10}$ já povoaram as primeiras posições das listas de assuntos mais comentados do Twitter Brasil - em alguns casos, do Twitter mundial.

8 Disponível em: http://www.instagram.com/p/ttiSrTD3XJ/?taken-by=valescapopozudaoficial. Acesso em: 6 jun. 2017.

9 Disponível em: http://www.instagram.com/p/ulVlsSD3fd/?tagged=valescanoraulgil. Acesso em: 6 jun. 2017.

10 Disponível em: http://www.instagram.com/p/qW2I5DD3Un/?tagged=valescapopozudanoestr elas. Acesso em: 6 jun. 2017. 
Quando isso ocorre, a artista costuma agradecer aos fãs, publicando em seus perfis imagens da posição alcançada pela hashtag no ranking.

Atenta aos benefícios para sua carreira decorrentes do trabalho voluntário dos fãs, Valesca divulga, com alguma frequência, momentos de sua intimidade para seus admiradores. Em junho de 2013, quando lançou sua primeira música de carreira solo, "Beijinho no ombro", Valesca convidou os "popofãs" para participarem de uma promoção na qual deveriam publicar um vídeo no YouTube cantando a música completa e uma foto no Instagram que fizesse referência à canção. Ela divulgou em seu perfil no Facebook instruções detalhadas do regulamento da competição, estipulando que os vencedores seriam aqueles que amealhassem o maior número de acessos e curtidas em suas postagens. ${ }^{11}$ Os primeiros colocados ganhariam, além de aparelhos celulares, o direito de passar um dia inteiro com a cantora. Assim, por meio dessa promoção, Valesca incentivou os fãs a divulgarem sua música nas redes sociais utilizando vídeos e imagens; em contrapartida, os premiava com a oportunidade de compartilhar um pouco do dia a dia da estrela.

Também no final de 2013, Valesca presenteou Gabriel, o fã que mais ligou para a rádio FM O Dia pedindo sua música "Beijinho no ombro". A cantora o levou para viajar em retribuição às demonstrações de "dedicação" e "carinho", materializadas nas insistentes ligações do fã para diversas rádios suplicando pela execução da música. Como parte das estratégias para conquistar a fidelidade de seus seguidores, Valesca publicou em seu perfil no Instagram uma foto com Gabriel, proporcionando visibilidade e estima ao fã resoluto. ${ }^{12} \mathrm{O}$ reconhecimento público por parte da celebridade reverberou de forma positiva entre seus seguidores, gerando comentários como: "Fico em ecstasy ao ver como você trata bem os seus fãs! Maravilhosa”. Entre os fãs, ser "reconhecido" pelo seu ídolo pode conferir um status elevado entre o fandom (MARWICK e BOYD, 2011), impulsionando atos similares de ativo engajamento em busca dessa distinção.

11 Disponível em: https://www.facebook.com/293341817377806/photos/a.296748000370521.76 967.293341817377806/588348727877112/?type=3\&theater. Acesso em: 6 jun. 2017.

12 Disponível em: https://www.instagram.com/p/f2kLwQD3cT/. Acesso em: 6 jun. 2017. 
Além de encontros individuais, Valesca também promove momentos de intimidade com grupos de admiradores. Encontros marcados com fãs já ocorreram em shopping centers, ${ }^{13}$ antes de shows ou mesmo durante churrascos. O "churrasco dos "popofãs", às vezes chamado de "popochurras", já realizado em diferentes cidades do país, ${ }^{14}$ tornou-se uma tradição. Organizado pela própria Valesca como forma de retribuição pelas inúmeras campanhas nas mídias sociais promovidas pelos seus seguidores, o evento oferece uma oportunidade singular para que seus mais dedicados fãs possam dividir momentos de intimidade com o ídolo. ${ }^{15}$ Os "popochurras" são celebrados pelos fãs, que se sentem "especiais" ao manterem contato direto com a cantora, sentimento este reforçado pelas fotografias compartilhadas na internet em que posam ao lado da celebridade que tanto admiram. Portais de notícias de celebridades, por sua vez, costumam utilizar fotografias desses eventos, abundantemente encontradas no perfil de Valesca, para produzir conteúdos que celebram a relação de afeto desenvolvida entre ídolo e fã. Com a publicação de tais fotografias e reportagens, todos conseguem impulsionar ainda mais o capital de visibilidade de que dispõem; não somente a celebridade, mas os próprios fãs.

A partir da análise da atuação da cantora nas mídias sociais, percebe-se que as estratégias diretas para motivar ações dos fãs diminuíram em meados de 2014, período que coincide com a assinatura do contrato com a gravadora Universal Music. Nos últimos anos, Valesca continua trazendo postagens fazendo referência direta aos fãs, mas não tem realizado promoções oferecendo prêmios em troca da divulgação de seu trabalho. Também diminuíram as postagens referentes a passeios, viagens e festas com seus fãs. Se, entre 2012 e 2013, eram recorrentes as publicações com "popofãs", marcando os perfis de cada um deles ou citando seus nomes, nos últimos anos, eles aparecem principalmente em

13 Disponível em: http://ego.globo.com/famosos/noticia/2012/04/de-roupa-comportada-valesca-popozuda-e-carregada-por-fas.html. Acesso em: 6 jun. 2017.

14 Disponível em: http://www.folhavitoria.com.br/entretenimento/blogs/na-balada/2015/06/valesca-popozuda-esta-em-vila-velha-fazendo-churrasco-com-fas/. Acesso em: 6 jan. 2017.

15 Disponível em: http://ego.globo.com/famosos/noticia/2013/04/valesca-popozuda-faz-churrasco-com-fas-amo-muito-tudo-isso.html. Acesso em: 6 jun. 2017. 
imagens de shows, acompanhados da hashtag \#popofas. ${ }^{16}$ Possivelmente, a atuação de uma estrutura de propaganda mais profissional e robusta oferecida pela gravadora com a qual assinou contrato, assim como os novos compromissos decorrentes desse novo momento profissional, é responsável pelo menor engajamento da cantora nesse tipo de dinâmica.

\section{Muito mais do que 5ínco Minutos: os kélovers e a cultura da promoção}

A youtuber Kéfera Buchmann, criadora do canal de vídeo de generalidades 5 inco Minutos, que conta com mais de 10 milhões de seguidores, ${ }^{17}$ também é notória pelas estratégias que adota para engajar seus fãs, conhecidos como "kélovers". Seus seguidores mais fiéis também a acompanham em outros projetos, ajudando na construção de uma carreira que transcendeu as mídias sociais e conquistou considerável retorno financeiro e visibilidade nos últimos anos.

Assim como Valesca, Kéfera retribui o empenho fundamental de seus fãs com transmissões ao vivo dedicadas aos seus seguidores, interações diretas via redes sociais, encontros presenciais, entre outras ações. Destaca-se, neste trabalho, as dinâmicas nos seguintes eventos envolvendo a youtuber e os "kélovers": a gravação do vídeo em comemoração à marca de oito milhões de inscritos no 5 inco Minutos em abril de 2016; o lançamento, naquele mesmo ano, do filme É fada!, estrelado por Kéfera; e a campanha de votação para o prêmio Kids Choice Awards, do canal de TV Nickelodeon, no qual a youtuber concorreu à categoria "Personalidade brasileira favorita". ${ }^{18}$

16 Disponível em: https://www.instagram.com/p/BRoJ_UylL14/?taken-by=valescapopozudaoficial. Acesso em: 6 jun. 2017.

17 Número de acessos em junho de 2017. Disponível em: https://www.youtube.com/ user/5incominutos. Acesso em: 6 jun. 2017.

18 Kéfera concorreu ao prêmio junto com a snapchatter ThaynaraOG e o também youtuber Luba, o vencedor da categoria. Disponível em: http://kca.mundonick.com.br/video/kca-personalidade-brasileira/pj8c64. Acesso em: 5 jun. 2017. 
Além de youtuber e escritora recordista de vendas, Kéfera empresta seu nome a linhas de joias, ${ }^{19}$ alimentos, ${ }^{20} \operatorname{cosméticos},{ }^{21}$ roupas $^{22}$ e outros produtos, além de já ter trabalhado como atriz de teatro e cinema, atividade que considera sua maior vocação. Para maximizar a exposição de seus empreendimentos, a youtuber costuma convocar seus fãs para que ajudem a alcançar metas que considera importantes. Um exemplo disso são os marcos ligados ao número de seguidores de seu canal de vídeo no YouTube. Cada vez que o 5 inco Minutos se aproxima de um novo milhão de inscritos, a celebridade recruta fãs e seguidores, por meio de seus perfis públicos on-line, para que a ajudem a angariar mais inscritos, acelerando, assim, a extrapolação do marco. O chamado de Kéfera costuma se disseminar rapidamente, gerando retweets que se multiplicam num efeito bola de neve. ${ }^{23}$

Quando alcança os objetivos almejados, a atriz e youtuber costuma celebrar em festas privadas ou por meio de vídeos comemorativos publicados em seu canal nos quais agradece o empenho e engajamento dos fãs. Porém, ao chegar à marca dos oito milhões de inscritos no 5 inco Minutos, Kéfera retribuiu o trabalho de seus seguidores abrindo espaço para um contato mais próximo e pessoal com eles. A youtuber informou pelo Twitter que estaria on-line em uma plataforma de bate-papo ${ }^{24}$ e que falaria ao vivo e em vídeo com seus fãs por meio do mecanismo de busca da própria rede social. ${ }^{25}$

19 Disponível em: http://www.keferaonline.com/2016/02/kefera-lanca-linha-de-joias-junto-com. html. Acesso em: 21 jun. 2017.

20 Disponível em: https://twitter.com/keferaon/status/691807696908128256. Acesso em: 21 jun. 2017.

21 Disponível em: https://studio35cosmeticos.lojaintegrada.com.br/batom-liquido-matteme-studio-35-by-kefera-buchmann. Acesso em: 21 jun. 2017.

22 Disponível em: http://roupas.mercadolivre.com.br/calcados-roupas/camisetas-dos-5inco-minutos-da-kefera. Acesso em: 21 jun. 2017.

23 Para angariar mais inscritos para o 5inco Minutos, os fãs fazem campanhas em sites de redes sociais, como é possível verificar nessa postagem. Disponível em: https://twitter.com/hashtag/ SeInscrevaNo5incoMinutos?src=hash. Acesso em: 5 jul. 2017.

24 No site omegle.com é possível conversar por meio de transmissão de vídeo simultânea com outros usuários on-line através da busca de hashtags ou termos que estejam sendo compartilhados no momento.

25 O vídeo de comemoração dos oito milhões de inscritos. Disponível em: https://www.youtube. com/watch?v=E_icNE825hw. Acesso em: 1 maio 2017. 
Na ocasião, Kéfera criou uma hashtag ${ }^{26}$ de referência, \#5INCOMINUTOS8MILHOES, e passou a conversar com pessoas que a utilizavam naquele momento. Nas curtas trocas, seus seguidores se mostraram surpreendidos pela atitude inusitada da youtuber. Durante o bate-papo informal, os fãs fizeram declarações de amor a Kéfera, contaram histórias de superação pessoal envolvendo conteúdos produzidos por ela e reforçaram promessas de fidelidade. Esse tipo de dinâmica, na qual fãs ajudam a youtuber a alcançar visibilidade e, em troca, recebem algum tipo de acesso especial à intimidade dela, se repetiu em inúmeras ocasiões. Essas práticas parecem indicar a existência de um processo de racionalização de afetos que mistura esfera pública e privada (ILLOUZ, 2012) e que é marcado pela aspiração de Kéfera à realização profissional.

Como último exemplo, é possível mencionar a indicação da youtuber como finalista do prêmio "Personalidade brasileira favorita 2017", promovido pelo canal de TV paga Nickelodeon e que teria o resultado do vencedor divulgado no evento Kids Choice Awards. À ocasião do anúncio da premiação, Kéfera iniciou uma campanha junto a seus fãs pedindo enfaticamente que votassem pelo próprio site do Nickelodeon e compartilhassem hashtags de sua indicação ao prêmio em sites de redes sociais para que, desse modo, obtivesse o maior número de menções e votos populares. Naquela mesma semana, a youtuber gravou um vídeo para seu canal no qual não somente explicava as regras da premiação, mas também anunciava que, se vencesse a disputa, realizaria uma festa para seu fandom: a "kélovers party". ${ }^{27} \mathrm{O}$ anúncio da festa teve como objetivo incentivar os fãs a trabalharem com mais afinco no processo de votação para que ela ganhasse o prêmio.

Durante o período de votação, Kéfera realizou muitos desafios e brincadeiras com seus seguidores no Twitter como forma de alavancar sua visibilidade na mídia social e angariar votos. Como uma das formas de

26 Postagens da youtuber informando sua ação e convidando seus fãs a participarem. Disponível em: https://twitter.com/Kefera/status/716785910931726337 e https://twitter.com/Kefera/status/716803984057626624. Acesso em: 5 jul. 2017.

27 Disponível em: https://www.youtube.com/watch?v=Yji5Oi0Kobs\&t=430s. Acesso em: 16 mar. 2017. 
contagem de votos era através da postagem (ou repostagem) das hashtags \#KCAPersonalidadeBR \#Kefera, a youtuber propôs, em diferentes ocasiões, a troca de retweets por ligações telefônicas diretas para os mais dedicados fãs. ${ }^{28}$ Ou seja, aqueles seguidores que publicassem a hashtag que dava votos a Kéfera teriam a oportunidade de ser escolhidos para estabelecer um contato exclusivo com ela por telefone. A resposta dos fãs foi contundente. Além de publicarem milhares de hashtags, conforme pedido pela celebridade, muitos seguidores suplicaram via Twitter por um contato direto de Kéfera, chegando até a publicar abertamente seus números de celular, mesmo sem a youtuber pedir.

Não é difícil constatar o fascínio que celebridades como Kéfera e Valesca exercem sobre seus fãs e como ele pode ser utilizado de modo produtivo pela própria celebridade para alavancar sua carreira. Mesmo sem ter sido eleita a "Personalidade brasileira favorita", as estratégias de persuasão de Kéfera, baseadas na oferta de um tipo de reconhecimento e intimidade aos fãs em troca do trabalho destes para aumentar a visibilidade da youtuber nas mídias sociais, obtiveram grande sucesso. Nesse sentido, tal como Baym e Burnett (2009) ressaltaram ao analisar a relação de bandas e fãs, é necessário olhar essa perspectiva de forma dialética: os fãs não são explorados, mas também não são os heróis da nova cultura da convergência.

\section{Considerações finais}

Não cabe no escopo deste artigo discutir o que Valesca e Kéfera representam para seus fãs, nem mesmo fazer qualquer tipo de julgamento moral acerca das práticas que ambas utilizam para convencer seus seguidores a ajudá-las na acumulação de capital de visibilidade (HEINICH, 2012). A possibilidade de acesso a alguma forma de intimidade ou obtenção de reconhecimento por parte de celebridades é um valor naturalizado na sociedade midiática atual, que transcende a cultura de celebridade em

28 Exemplos de publicações da youtuber Kéfera propondo ligações em troca de retweets. Disponível em: https://twitter.com/Kefera/status/828871523683467264 e https://twitter.com/Kefera/ status/8381793383778887745. Acesso em: 7 jul. 2017. 
particular. Dito de outro modo, os fãs também obtêm ganho simbólico de outra ordem com tais dinâmicas.

Certamente, a proposta de que a mídia tem um tipo disperso de poder estruturado no mito de que representa uma ponte para "o centro do social" é uma contribuição valiosa para esse debate (COULDRY, 2012). Segundo essa perspectiva, o que é ligado às categorias do mundo da mídia, tais como "ao vivo", "realidade", "personalidade midiática", é considerado mais relevante do que o que não é. Ou seja, a mídia é vista como uma força hierárquica que divide o mundo; ela incorpora o social. Pertencer a esse mundo, mesmo que por meio de um breve contato com uma celebridade, é valorizado por uma parcela significativa da sociedade.

Ao mesmo tempo, relações pessoais e profissionais contemporâneas são cada vez mais atravessadas pelo afeto; um tipo de afeto que, segundo Illouz (2012), é racionalizado e mercantilizado. Dentro desse contexto, argumentamos aqui que a possibilidade de aproximação entre ídolos e fãs tem se tornado cada vez maior, especialmente na última década. Em muitos casos, tal proximidade é atravessada por uma administração racionalizada de afetos inserida numa lógica de criação de formas de capital economicamente conversíveis ligadas à indústria do entretenimento. Nesse sentido, Turke (2014) chama atenção para a crescente importância do fã como força de trabalho dentro de uma "economia da dádiva".

Segundo Morin $(1989,1997)$, no século XX, a cultura de massa reforçava o caráter de divindade de grandes estrelas, ao mesmo tempo que buscava humanizá-las através da divulgação de suas vidas privadas. Assim, capas de revistas estampavam notícias do cotidiano dos neo-olimpianos buscando propiciar uma identificação do público com aqueles que aparentavam ser inalcançáveis. No contexto atual das mídias digitais, contudo, observa-se uma nova configuração na qual a aproximação de celebridades com fãs não é necessariamente mediada pela atuação de profissionais da indústria do entretenimento. Se, no passado, não existia uma expectativa concreta, por parte do fã, de contato direto com estrelas 
de cinema, astros do rock ou mesmo atores de telenovela, atualmente, existe quase uma demanda por esse tipo de acesso, conforme indica o considerável crescimento recente de webcelebridades (KHAMIS, ANG e WELLING, 2016; SENFT, 2012). Ao mesmo tempo, a possibilidade de se estabelecer esse tipo de relação afetiva abre novas oportunidades para que a celebridade amplie seu capital de visibilidade e para que o fã ganhe algum tipo de "reconhecimento" ligado ao mundo da mídia.

\section{Referências}

BAYM, N. Fãs ou amigos? Enxergando a mídia social como fazem os músicos. Matrizes, v. 7, n. 8, p. 13-46, 2013.

The new shape of online community: the example of Swedish independent music fandom. First Monday, v. 12, n. 8, ago. 2007.

.; BURNETT, R. Amateur experts: international fan labour in Swedish independent music. International Journal of Cultural Studies, v. 12, n. 5, p. 433-449, 2009. BOORSTIN, D. The image: a guide to pseudo-events in America. Nova York: Vintage Books, 1992. (1. ed. 1961).

BRÄUCHLER, B.; POSTILL, J. Theorising media and practice. Nova York: Berghahn Books, 2010.

BRAUDY, L. The frenzy of renown: fame and its history. Oxford: Oxford University Press, 1986.

CAMPANELLA, B. Os olhos do grande irmão: uma etnografia dos fãs do Big Brother Brasil. Porto Alegre: Sulina, 2012.

COELHO, M. C. P. A experiência da fama: individualismo e comunicação de massa. Rio de Janeiro: FGV, 1999.

COLLINS, S. Making the most out of 15 minutes: reality TV's dispensable celebrity. Television 6 New Media, v. 9, n. 2, p. 87-110, 2008.

COULDRY, N. Media, society, world: social theory and digital media practice. Cambridge: Polity Press, 2012.

DYER, R. Stars. Londres: BFI Publishing, 1998.

ESTATÍSTICAS DE TV por assinatura no Brasil. Teleco. Inteligência em Telecomunicações. [s. 1.], [s. d.]. Disponível em: http://www.teleco.com.br/rtv.asp. Acesso em: 5 jul. 2017.

GAMSON, J. Claims to fame: celebrity in contemporary America. Berkeley: University of California Press, 1994. 
GLOBO EMITE COMUNICADO anunciando o fim do portal 'Ego'. O Dia, 17 abr. 2017. Disponível em: http://odia.ig.com.br/brasil/2017-04-17/globo-emite-comunicado-anunciando-o-fim-do-portal-ego.html. Acesso em: 20 abr. 2017.

GRINDSTAFF, L.; MURRAY, S. Reality celebrity: branded affect and the emotion economy. Public Culture, v. 27, n. 1, p. 109-135, 2015.

HEINICH, N. De la visibilité: excellence et singularité en régime médiatique. Paris: Gallimard, 2012.

HOLMES, S.; JERMYN, D. (Orgs.). Understanding reality television. Londres: Routledge, 2004.

ILLOUZ, E. O amor nos tempos do capitalismo. Rio de Janeiro: Zahar, 2012.

KHAMIS, S.; ANG, L.; WELLING, R. Self-branding, 'micro-celebrity' and the rise of Social Media Influencers. Celebrity Studies, v. 8, n. 2, p. 191-208, ago. 2016.

KRAMP, L.; CARPENTIER, N.; HEPP, A.; TRIVUNDŽA, I. T.; NIEMINEN, H.; KUNELIUS, R.; OLSSON, T.; SUNDIN, E.; KILBORN, R. Media practice and everyday agency in Europe. Bremen: Edition Lumière, 2014.

LANGER, J. Television's personality system. In: MARSHALL, P. D. (Org.). The celebrity culture reader. Nova York: Routledge, 2006. p. 181-195.

LÖWENTHAL, L. The triumph of mass idols. In: MARSHALL, P. D. (Org.). The celebrity culture reader. Nova York: Routledge, 2006. p. 124-152.

MARSHALL, P. D. Celebrity and power: fame in contemporary culture. Minneapolis: University of Minnesota Press, 1997.

MARWICK, A.; boyd, d. To see and be seen: celebrity practice on Twitter. Journal of Research into New Media Technologies, v. 17, n. 2, p. 139-158, 2011.

MOLE, T. Byron's romantic celebrity: industrial culture and the hermeneutic of intimacy. Nova York: Springer, 2007.

MORIN, E. As estrelas: mito e sedução no cinema. Rio de Janeiro: José Olympio, 1989. Cultura de massas no século XX: o espírito do tempo. Rio de Janeiro: Forense Universitária, 1997.

REIN, I. J.; KOTLER, P.; STOLLER, M. R. High visibility: the making and marketing of professionals into celebrities. Chicago: Contemporary Publishing Company, 1997.

ROJEK, C. Celebrity. Londres: Reaktion Books, 2001.

SENFT, T. Microcelebrity and the Branded Self. In: HARTLEY, J.; BURGESS, J.; BRUNS, A. (Orgs.). Blackwell Companion to New Media Dynamics. Malden: Wiley-Blackwell, 2012. p. 346-354.

STERNHEIMER, K. Celebrity culture and the American dream: stardom and social mobility. Nova York: Routledge, 2011.

STRATE, L. Heroes: a communication perspective. In: DRUCKER, S. J.; CATHCART, R. S. (Orgs.). American heroes in a media age. Cresskill: Hampton, 1994. p. 15-23.

TOLSON, A. The history of television celebrity: a discursive approach. Celebrity Studies, v. 6, n. 3, p. 341-354, jul. 2015.

TURKE, T. Fan work: labor, worth, and participation in fandom's gift economy. Transformative Works and Cultures, v. 15, p. 1-8, 2014. 
TURNER, G. The mass production of celebrity: 'celetoids,' reality TV and the 'demotic turn'. International Journal of Cultural Studies, v. 9, n. 2, p. 153-165, 2006. . Understanding celebrity. Londres: Sage, 2004.

.; BONNER, F.; MARSHALL, P. D. Fame games: the production of celebrity in Australia. Melbourne: Cambridge University Press, 2000.

VAN KRIEKEN, R. Celebrity society. Oxon: Routledge, 2012.

WEINSTEIN, D. Art versus commerce: deconstructing a (useful) romantic illusion. In: KELLY, K.; MCDONNELL, E. (Orgs.). Stars don't stand still in the sky: music and myth. Nova York, 1999.

\section{Sobre os autores}

Bruno Campanella - Professor do Departamento de Estudos Culturais e Mídia da Universidade Federal Fluminense (UFF) e professor do PPGCOM da mesma universidade. Doutor em Comunicação e Cultura pela Universidade Federal do Rio de Janeiro e mestre em Comunicação Transnacional e Mídia Global pelo Goldsmiths College, University of London.

Joana d'Arc de Nantes - Doutoranda em Comunicação no Programa de Pós-Graduação da UFF. Formada em Produção Cultural e em Estudos de Mídia pela UFF.

Paula Fernandes - Mestranda em Comunicação, na linha de pesquisa Mídia, Cultura e Produção de Sentido, na UFF. Graduada em Comunicação Social, com habilitação em Jornalismo, pela Universidade Federal de Viçosa (UFV).

Data de submissão: 31/07/2017

Data de aceite: $21 / 02 / 2018$ 